\title{
Estudio físico-químico y microbiológico de la fermentación de aceitunas verdes arbequinas
}

\author{
Por J.E. de la Torre, E.R. Moya, E. Bota y J. Sancho* \\ Escola Superior D’Agricultura de Barcelona. Dept. Indústries Agroalimentàries. Comte d'Urgell 187. 08036 Barcelona.
}

\section{RESUMEN}

Estudio físico-químico y microbiológico de la fermentación de aceitunas verdes arbequinas.

A pesar del creciente consumo, existe poca información disponible sobre las aceitunas verdes en salmuera, sobre todo de la variedad Arbequina. Con este producto se suelen presentar problemas de conservación debido a su baja acidez y valores relativamente altos de $\mathrm{pH}$. Se ha realizado un estudio comparativo, con aceituna Arbequina, de fermentación espontánea y de fermentación dirigida utilizando cepas de bacterias lácticas, aisladas de muestras comercializadas de estas olivas, que se han identificado en todos los casos como Lactobacillus plantarum.

En el presente trabajo se ofrecen los resultados obtenidos en la determinación de los principales parámetros físico-químicos y microbiológicos de las aguas de lavado de las aceitunas y del caldo de fermentación a lo largo del proceso.

A partir de los resultados expuestos se proponen algunos cambios significativos en la técnica usual para la fermentación de la aceituna verde Arbequina.

PALABRAS-CLAVE: Aceituna verde arbequina - Estudio físico-químico - Estudio microbiológico - Fermentación.

\section{SUMMARY}

Physical, chemical and microbiological studies of the fermentation of Arbequina green olives.

Despite the growing market of the "Arbequina" cultivar of green table olive, there are some trobles related to the low acidity and relative high $\mathrm{pH}$ values in the finished product.

A comparative study has been carried with this cultivar in spontaneous and controlled fermentation, using strains of lactic bacteria isolated from marketed samples, wich has been identified allways as Lactobacillus plantarum.

Starting from the main physical, chemical and microbiological parameters dettermined in the experiences, some changes in the usual technique of fermentation for the «Arbequina» olives are proposed.

KEY-WORDS: Arbequina green olive - Fermentation - Microbiological study - Physico-chemical study.

\section{INTRODUCCION}

El tipo de elaboración de las aceitunas verdes Arbequinas puede incluirse dentro de las «aceitunas verdes en salmuera", que reciben la siguiente definición específica, según la Reglamentación Técnico Sanitaria de 1983: son las tratadas directamente en salmuera y conservadas por fermentación natural.

En la elaboración de aceitunas de mesa es necesario suprimír total o parcialmente el intenso sabor amargo de los frutos verdes (5) (3) (7) (11). Este endulzado se puede conseguir por la eliminación del glucósido amargo oleoeuropeína del fruto, mediante un «cocido" con solución de sosa diluida (estilo sevillano o español), o mediante sucesivos lavados con agua (aceitunas en salmuera).

La fermentación de las aceitunas verdes en salmuera se caracteriza, en general, por estar provocada fundamentalmente por levaduras, con gran desprendimiento de gas. La acidez que se desarrolla durante el proceso es baja, inferior a $0,5 \%$ en ácido láctico, y un $\mathrm{pH}$ relativamente elevado, que de no encontrarse debidamente ajustado puede dar lugar a problemas de conservación del producto (1).

Existen una serie de aspectos a tener en cuenta en el momento de realizar una fermentación dirigida en las aceitunas:

A) Variedad: Es un factor determinante en la evolución de la fermentación. Por lo general, las aceitunas que se destinan a la obtención de aceite, como es el caso de la Arbequina, suelen presentar ciertas dificultades al desarrollo de bacterias lácticas durante la fermentación espontánea (1).

B) Inóculo: Se considera a Lactobacillus plantarum como la bacteria responsable de la fermentación láctica de las aceitunas y hay numerosos trabajos que lo confirman (2) (9) (8), e incluso que demuestran la mayor eficacia de esta especie frente a otras bacterias lácticas (1).

C) Efecto inhibidor de los polifenoles: La presencia de sustancias inhibidoras de bacterias en la pulpa del fruto ha sido confirmada por diversos autores (4) (3) (6), y aunque no hay un acuerdo general en la atribución definitiva de este efecto bacteriostático, se ha demostrado que esta propiedad se manifiesta en la oleoeuropeína y algunos de los productos de su hidrólisis: el ácido elenólico y la aglucona. Por otra parte, Garrido y cols. han comprobado que las bacterias lácticas pueden utilizar la oleoeuropeína como 
fuente de carbono si la concentración es inferior a $0.2 \%$, pero en cambio a concentraciones de $0.4 \%$ ya resulta inhibidora del crecimiento. Estos resultados se han verificado (8) (11) con distintas cepas de Lactobacillus plantarum en las cuales se han obtenido distintos grados de resistencia y niveles de utilización.

D) Técnica fermentativa: Para dirigir la fermentación de las aceitunas arbequinas se han practicado dos técnicas distintas. En la primera se inocula directamente la salmuera con la cepa seleccionada de $L a c$ tobacillus plantarum. En la segunda, el fruto en salmuera se somete a un calentamiento a $74^{\circ} \mathrm{C}$ durante 3 minutos y posteriormente, una vez enfriado, se inocula con la cepa seleccionada. Esta última técnica se ensayó con la variedad Manzanilla, tratando los frutos previamente con lejía, al estilo sevillano, demostrándose que fermentaban mejor y más rápidamente que otras del mismo lote sin el calentamiento (1). En otras experiencias con la misma variedad (10), se obtiene una elevada acidez de la salmuera y con ello un pH más bajo que el ordinario en este tipo de elaboración.

En definitiva, no se ha podido demostrar cuál es el efecto del calentamiento sobre los compuestos antimicrobianos, si bien Fleming y cols. sostienen la teoría de que este tratamiento destruye el sistema enzimático que hidroliza la oleoeuropeína, evitándose así la formación de los compuestos de su hidrólisis a los que se atribuye la mayor actividad bactericida.

En este trabajo, se realiza un seguimiento de la fermentacion espontánea de las aceitunas verdes Arbequinas, según la práctica tradicional de su elaboración en Cataluña, y se plantea la posibilidad de modificar el proceso a fin y efecto de conseguir una fermentación dirigida con Lactobacillus plantarum, que diera lugar a unos valores de acidez y pH más adecuados para una correcta conservación, intentando mejorar con ello las características organolépticas del producto.

\section{MATERIAL Y METODOS}

Las experiencias se han realizado a nivel de laboratorio, y se han utilizado como fermentadores 6 bidones idénticos de P.V.C. de boca ancha, de 10 litros de capacidad total, para 7,7 Kg de aceituna y 5,5 I de salmuera. Los bidones están provistos de doble cierre (tapa y obturador) para evitar el contacto directo de las aceitunas con el aire. Todas las experiencias se han realizado por duplicado.

\subsection{Aceitunas}

La muestra inicial consta de $60 \mathrm{Kg}$ de aceitunas verdes de la variedad Arbequina (Olea europeae var. ilerdensis), que ha sido recogida manualmente en la población leridana de Les Borges Blanques.

\subsection{Microorganismos}

Para estas experiencias se ha empleado una cepa de Lactobacillus plantarum que había sido aislada de forma testimonial del líquido de gobierno de aceitunas arbequinas fermentadas comercializadas. A esta cepa, adaptada ya a la variedad de aceituna, se le determinó previamente su capacidad de acidificación y tolerancia a la sal, requisitos indispensables para considerarla un buen inóculo (2) (9) (8) (11).

\subsection{Muestreo y controles}

Todos los controles físico-químicos y microbiológicos se realizan sobre la salmuera de fermentación siguiendo técnicas de análisis establecidas (2) (10). Se determinan periódicamente para cada uno de los fermentadores los siguientes parámetros físico-químicos de la salmuera: $\mathrm{pH}$, acidez libre y polifenoles, como máximos exponentes de la fermentación; el contenido de cloruro sódico, por su importancia en la posible conservación del producto, y los azúcares reductores como indicadores del final de la fermentación. Los controles microbiológicos se centran en los recuentos de los microorganismos más representativos de las fermentaciones de aceitunas: Bacterias gramnegativas no esporuladas, levaduras y lactobacilos.

Los medios de cultivo empleados para cada tipo microbiano han sido: Agar Bilis Rojo-Violeta (ADSA=MICRO), Agar Sabouraud (ADSA=MICRO) y Agar MRS $(A D S A=M I C R O)$ con nystatina, respectivamente. Durante el período de los lavados se determina la cantidad de polifenoles que son eliminados diariamente y la población de bacterias gramnegativas que se desarrolla en cada uno de los lavados.

\subsection{Metodología}

Una vez seleccionado y escogido el fruto, se colocan $7,7 \mathrm{Kg}$ en cada uno de los seis fermentadores, para iniciar una serie de lavados estáticos con agua, que se renueva cada 24 horas, durante 9 días sucesivos. Después de último lavado se procede a realizar tres experiencias diferentes, con repetición. Las condiciones para cada una de estas tres experiencias, que se han realizado por duplicado, se detallan a continuación:

2.4.1 Experiencia 1: Corresponde al proceso tradicional de fermentación de las aceitunas verdes Arbequinas en salmuera. A las aceitunas se les coloca directamente la salmuera del $7 \%(\mathrm{p} / \mathrm{v} \mathrm{CINa})$, preparada exclusivamente con agua y cloruro sódico, que completa el volumen total de recipiente, y que impide la presencia de la capa de aire en la superficie. Estos fermentadores servirán como testigos frente a las otras dos experiencias.

2.4.2 Experiencia 2: Las aceitunas son tratadas también con salmuera al $7 \%(\mathrm{p} / \mathrm{v} \mathrm{CINa)}$. Al cabo de tres días se inoculan con un cultivo puro de Lactobacillus plantarum, en una proporción del $2 \%(\mathrm{v} / \mathrm{v})$ en los fermentadores, tal y 
como recomienda el Instituto de la Grasa y sus Derivados, empleando como base para el inóculo Caldo Infusion de Levadura-Glucosa tamponado a pH 5,57 (2) (9).

2.4.3 Experiencia 3: El fruto, después de los lavados, es sumergido mediante una cestilla metálica dentro de un recipiente con agua y calentado a una temperatura de $74^{\circ} \mathrm{C}$, durante 3 minutos. Posteriormente se devuelven las aceitunas a los fermentadores y se introduce la salmuera del $7 \%$. A los tres días se inocula con Lactobacillus plantarum de igual forma que en la experiencia anterior.

Una vez preparadas las tres experiencias, se colocaron los fermentadores en una galería cubierta, donde la temperatura media diurna se sitúa entre los 22 y $25^{\circ} \mathrm{C}$.

\section{RESULTADOS Y DISCUSION}

Los resultados obtenidos en las dos repeticiones de cada experiencia se han promediado y se exponen de forma gráfica para facilitar la comparación entre el patrón y las dos variaciones experimentales.

\subsection{Aguas de Lavado}

En las aguas de lavado, se ha comprobado que la cantidad de polifenoles que se difunde es muy pequeña, como queda expuesto en la gráfica $n^{\circ} 1$. Parece ser, por tanto, que la práctica de someter a las aceitunas a lavados estáticos, previos a la colocación de las aceitunas en salmuera, no produce un sustancial desamargado de los frutos. Por otra parte, en cada lavado estático de 24 horas se obtiene una abundante y creciente población de bacterias gramnegativas (véase gráfica $n^{\circ} 1$ ), hecho que podría resultar peligroso, por la probable relación de estos microorganismos con la alteración denominada «alambrado» (2).

Aguas de lavado Polifenoles y Bacterias G(-)

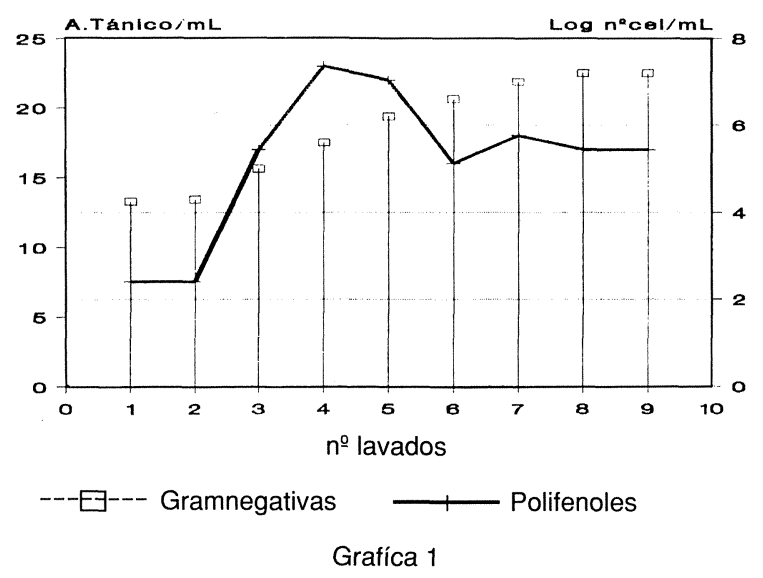

Evolución de la población de bacterias gramnegativas (expresadas en $\log \mathrm{n}^{\circ} \mathrm{cel} / \mathrm{mL}$ ) y polifenoles en $\mathrm{mg}$ de ácido tánico por $\mathrm{mL}$ de agua en las aguas de los sucesivos lavados de los lotes sin tratamiento ni inóculo.

\subsection{Experiencia 1 (Fermentación tradicional).}

Durante toda la fermentación, se ha comprobado que prácticamente sólo habia un único tipo de levadura que era la que dominaba el proceso fermentativo, y aunque se han aislado otros tipos, su presencia es sólo testimonial. Esta especie de levadura, que sería la más representativa del proceso de fermentación de las aceitunas verdes Arbequinas, ha sido identificada como Hansenula anomala. Sólo al final de la fermentación se observó el abundante desarrollo de otro tipo de levadura. Esta especie ha sido identificada como Torulopsis inconspicua, que posee metabolismo oxidativo y puede provocar velos o películas en la superficie de los fermentadores. En ninguno de los dos fermentadores se ha observado el desarrollo de bacterias lácticas. En la gráfica no 2 se muestra la evolución de la población de levaduras en las tres experiencias.

\section{Levaduras}

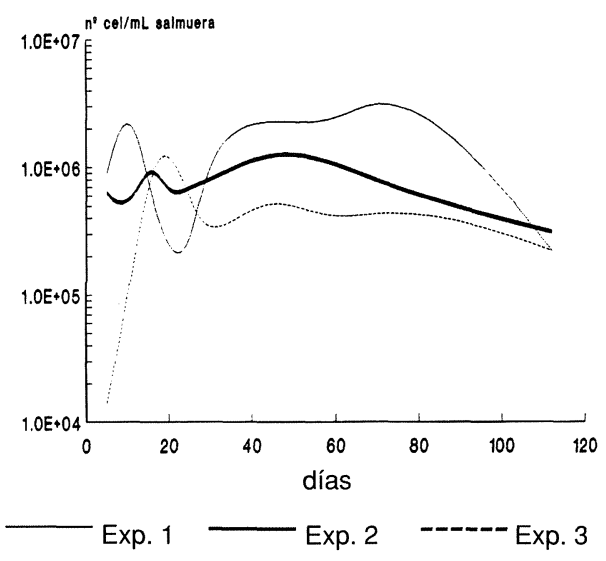

Gráfica 2

Evolución de la población promedio de levaduras en las tres series de

\subsection{Experiencias 2 y 3 (Fermentaciones dirigidas)}

Ni en los fermentadores de la experiencia 2, que habían sido inoculados con Lactobacillus plantarum, ni en los fermentadores de la experiencia 3 , en los que también se había inoculado, tras el calentamiento del fruto a $74^{\circ} \mathrm{C}$ durante 3 minutos, se detecta el crecimiento de LactobaciIlus plantarum inoculado, ni de otra bacteria láctica.

La flora microbiana que se desarrolla en estos fermentadores está compuesta por bacterias gramnegativas (gráfica $n^{\circ} 3$ ) y levaduras que siguen un desarrollo similar al de los fermentadores de la experiencia 1, tal y como se puede comprobar en las correspondientes gráficas.

Se ha comprobado el potente efecto inhibidor que ejercen los polifenoles sobre Lactobacillus plantarum. Al colocar una fina porción de pulpa en una placa donde ha crecido dicho microorganismo, en medio Agar Extracto de 
levadura-Glucosa y Malta (ADSA=MICRO), se produce una amplia zona de inhibición alrededor de la porción de aceituna. En la salmuera el efecto inhibidor de los polifenoles debe ser aún mayor, pues de por sí la salmuera es ya un medio hostil para el crecimiento de los lactobacilos debido a su pobreza en nutrientes y su alto contenido en sal:

Ninguna de las dos especies de levaduras aisladas de las salmueras de fermentación son inhibidas por los polifenoles. Por este motivo, los microorganismos predominantes en la fermentación de este tipo de aceitunas son las levaduras.

A la vista de los resultados de esta experiencia, es fundamental destacar la importancia del factor varietal. Las aceitunas Arbequinas son de maduracion más tardía que las aceitunas Manzanilla, y es muy posible que en el momento de su recolección la oleuropeína estuviera ya hidrolizada, habiéndose formado aglucona y ácido elenólico, que son compuestos termorresistentes y de potente efecto inhibidor. Por lo tanto, el calentamiento no ha tenido ningún efecto, como se hace evidente al comparar la evolución de la flora de levaduras (gráfica $n^{\circ}$ 2) y de bacterias (gráfica $\mathrm{n}^{\circ} 3$ ) en las tres experiencias.

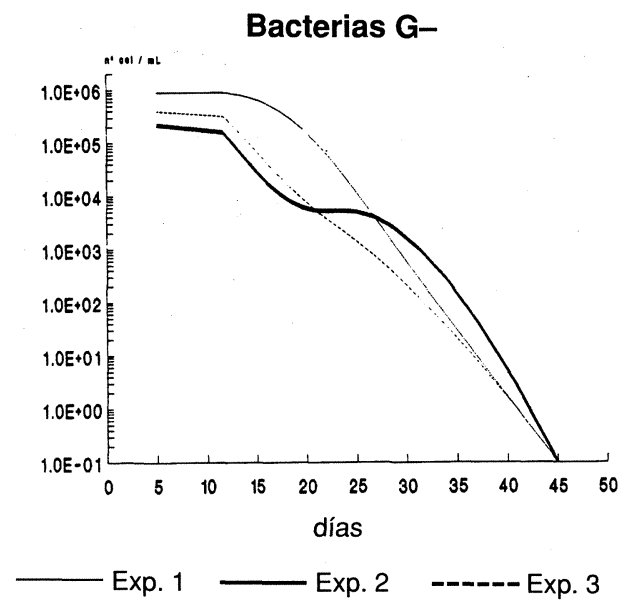

Gráfica 3

Evolución de la población promedio de bacterias G- en las tres series de tratamiento.

\subsection{Evolución de los parámetros físico-químicos.}

Debido a que no se produce una fermentación láctica en ninguna de las tres experiencias, la evolución de los parámetros físico-químicos de la salmuera es muy similar en todos los fermentadores.

3.4.1 pH: La evolución de este parámetro en las tres experiencias se expone en la gráfica $n^{\circ} 4$. En los primeros dias de la fermentación, se produce un importante descenso de $\mathrm{pH}$, debido al desarrollo de las bacterias gramne- gativas que producen anhídrido carbónico, hidrógeno, ácido acético, ácido láctico y etanol. El pH en los 20 primeros días, cuando el desarrollo de gramnegativas en la salmuera es muy significativo, desciende cerca de dos unidades. Posteriormente el $\mathrm{pH}$ no sufre variaciones especialmente significativas: baja ligeramente hasta los 30 días de fermentación, y después prácticamente se estabiliza con ligeras oscilaciones, en torno a $\mathrm{pH} 5$, hasta el final de la fermentación.

3.4.2 Acidez libre: En las tres experiencias, la acidez que se alcanza al final de la fermentación es muy baja, como puede observarse en la gráfica $n^{\circ} 4$, y no llega en ningún fermentador a los $0,3 \mathrm{~g}$ de ácido láctico por $100 \mathrm{ml}$ de salmuera. Al no existir crecimiento de bacterias lácticas no se produce acidificación de la salmuera. La pequeña cantidad de acidez producida, proviene en gran medida de los propios ácidos orgánicos presentes en la pulpa de las aceitunas que se difunden en la salmuera.

\section{Acidez libre y pH}

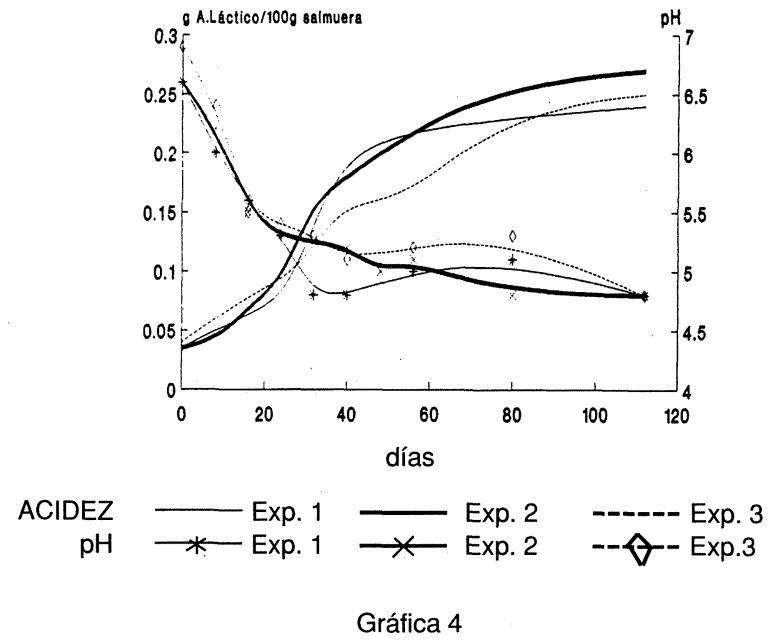

Evolución del pH y la acidez libre, esta última expresada en gramos de ácido láctico por $100 \mathrm{~mL}$ de salmuerà.

3.4.3 Cloruro Sódico: La concentración inicial del 7\% (p/v) de CINa en las salmueras, se estabiliza al final de la fermentación en un valor inferior al $5 \%$, como queda puesto de manifiesto en la gráfica $n^{\circ} 5$. Esta concentración de sal, unido al elevado $\mathrm{pH}$ que tienen las salmueras, puede ser no suficiente para prevenir el desarrollo de microorganismos indeseables, ni para asegurar una larga conservación del producto. Sería pues aconsejable, en este tipo de fermentaciones, emplear salmueras más concentradas y acidificar ligeramente con ácido acético o láctico.

3.4.4 Polifenoles: En la gráfica $n^{\circ} 6$, puede observarse la evolución de los polifenoles durante la fermentación y la difusión de estos compuestos en la salmuera. Entre los 80 y 110 días la cantidad que se difunde es muy pequeña debido a que se alcanza un equilibrio entre los polifenoles 


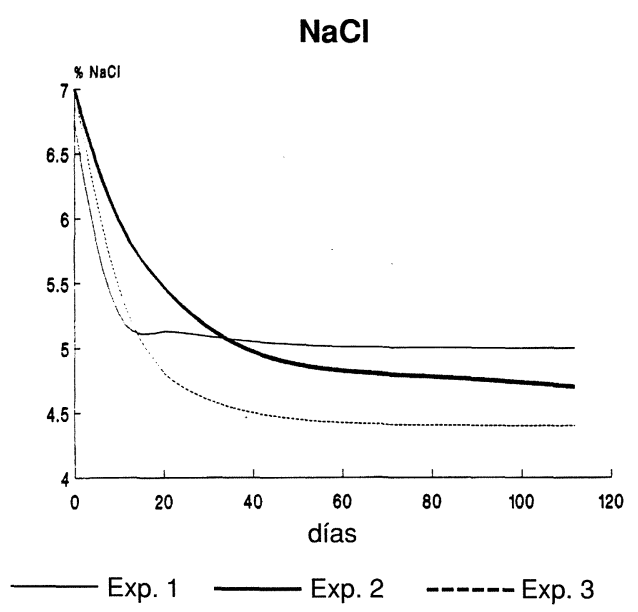

Gráfica 5

Evolución de la salmuera expresada en porcentaje $(p / v)$ de cloruro sódico a lo largo del tiempo.
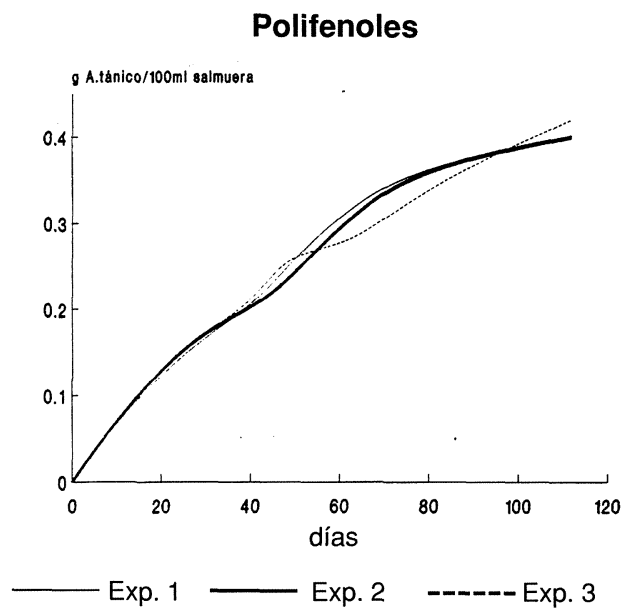

Gráfica 6

Evolución de la concentración de polifenoles expresados en gramos de ácido tánico por $100 \mathrm{~mL}$ de salmuera.

que contiene el fruto y los que se han difundido en la salmuera. En este momento es cuando los frutos han perdido gran parte de su amargor inicial y son perfectamente aptos para el consumo.

\section{CONCLUSIONES}

Los lavados estáticos a los que se someten los frutos antes de su salazón, producen una eliminación de polifenoles del fruto prácticamente despreciable, mientras que se favorece el desarrollo de bacterias gramnegativas productoras del «alambrado". La supresión de estos lavados estáticos no debe suponer ninguna complicación, aunque siempre se debe realizar un lavado dinámico, de corta duración, para eliminar la suciedad de los frutos.

Las levaduras son los microorganismos responsables de la fermentación de las aceitunas Arbequinas verdes en salmuera. Esta fermentación produce una baja acidez y un $\mathrm{pH}$ relativamente elevado. Será preferible, por tanto, utilizar una salmuera de elevada concentración y con un pH corregido para evitar el posible crecimiento de microorganismos indeseables.

Los resultados de las fermentaciones dirigidas han puesto de manifiesto la dificultad de realizar con éxito una fermentación láctica en las aceitunas verdes Arbequinas. Los resultados de la experiencia de fermentación dirigida en aceitunas previamente calentadas, hace pensar que los causantes de la inhibición del Lactobacillus plantarum han sido los productos de la hidrólisis de la oleuropeína.

Se pone de manifiesto la importancia del factor varietal, ya que mientras que en la Manzanilla, el calentamiento del fruto facilita la fermentación láctica, no ocurre igual en la variedad Arbequina.

\section{BIBLIOGRAFIA}

1. Etchells, J.L., Borg, A.F., Kittel, J.D., Bell, T.A. y Fleming, H.P. (1966)."Pure culture fermentation of green olives».- Appl. Microbiol. 14, $1027-$ 1041.

2. Fernández Díez, M. (1985).-Unidad Estructural de Investigación de Química, Microbiología y Tecnología de Aceitunas de Mesa.-«Biotecnología de la Aceituna de Mesa".-Instituto de la Grasa y sus Derivados (C.S.I.C.), Sevilla.

3. Fleming, H.P. y Etchells, J.L. (1967).-«Ocurrence of an inhibitor of lactic acid bacteria in green olives ".-Appl. Microbiol. 15, 1178-1184

4. Fleming, H.P., Walter, W.M:, y Etchells, J.L. (1973).- «Antimicrobial properties of oleuropein and products of its hydrolysis from green olives".Appl. Microbiol. 26, 777-782.

5. García García, P., Durán Quintana, M.C., Brenes Balbuena, M. y Garrido Fernández, A. (1992)—-Lactic fermentation during the storage of 'Alorena' cultivar untreated green table olives".-J Appl. Bacteriol. 73, 324-330

6. Garrido Fernández, A. y Vaughn, R.H. (1978).-Utilization of oleuropein by microorganisms associated with olive fermentations". -Can. J. Microbiol. 24, 680-684.

7. Harrigan, W.F. y McCance M. E. (1979).— «Métodos de laboratorio en Microbiología de alimentos y productos lácteos».-Ed. Academia, León.

8. Rodríguez de la Borbolla y Alcalá, J.M., Gómez Herrera, C. e Izquierdo Tamayo, A. (1952). - «El uso de cultivos puros de lactobacilos en el aderezo de aceitunas verdes". -Grasas y Aceites 3, 91-94 .

9. Rodríguez de la Borbolla y Alcalá, J.M., Gómez Herrera, C., e Izquierdo Tamayo, A. (1953). - «Estudio sobre el aderezo de aceitunas verdes. XI. Empleo de cultivos puros de lactobacilos".-An. Real Soc. Españ. Fís. Quím. 50-B, 497-504.

10. Rodríguez de la Borbolla y Alcalá, J.M., González Pellissó, F. y González Cancho, F. (1971). - «Aceitunas verdes y de color cambiante en salmuera |». -Grasas y Aceites 6, 455-463.

11. Ruiz Barba, J.L. y Jiménez Díaz, R. (1988). - Oleuropeína: Efecto bactericida sohre Lactobacillus plantarum».-Ponencia presentada en la VI Reunión Científica de Microbiología de los Alimentos, Facultad Veterinaria, Universidad Complutense de Madrid.

(Recibido: Marzo 1993) 